\title{
A child with acute encephalopathy associated with quadruple viral infection
}

\author{
Keiko Nakata ${ }^{1}$, Mitsuru Kashiwagi ${ }^{2}$, Midori Masuda ${ }^{2}$, Seiji Shigehara ${ }^{2}$, Chizu Oba ${ }^{2}$, Shinya Murata ${ }^{2}$, \\ Tetsuo Kase ${ }^{1}$ and Jun A. Komano ${ }^{1,3}$ *
}

1 Department of Infectious Diseases, Osaka Prefectural Institute of Public Health, Osaka, Japan

${ }^{2}$ Department of Paediatrics, Hirakata City Hospital, Hirakata, Japan

${ }^{3}$ Department of Clinical Laboratory, National Hospital Organization Nagoya Medical Center, Nagoya, Japan

Edited by:

John R. Mytinger, The Ohio State

University, USA

Reviewed by:

Vincenzo Salpietro, Chelsea and

Westminster Hospital, UK

Jonathan Robert Honegger, The Ohio

State University, USA

*Correspondence:

Jun A. Komano, National Hospital

Organization Nagoya Medical Center,

4-1-1 Sannomaru, Naka-ku, Nagoya

460-0001, Japan

e-mail:komano@nnh.hosp.go.jp
Pediatric acute encephalopathy (AE) was sometimes attributed to virus infection. However, viral infection does not always result in AE. The risk factors for developing infantile AE upon virus infection remain to be determined. Here, we report an infant with AE co-infected with human herpesvirus-6 (HHV-6) and three picornaviruses, including coxsackievirus A6 (CVA6), Enterovirus D68 (EV-D68), and human parechovirus (HPeV). EV-D68 was vertically transmitted to the infant from his mother. CVA6 and HPeV were likely transmitted to the infant at the nursery school. HHV-6 might be re-activated in the patient. It remained undetermined, which pathogen played the central role in the AE pathogenesis. However, active, simultaneous infection of four viruses should have evoked the cytokine storm, leading to the pathogenesis of AE. Conclusion: an infant case with active quadruple infection of potentially AE-causing viruses was seldom reported partly because systematic nucleic acid-based laboratory tests on picornaviruses were not common. We propose that simultaneous viral infection may serve as a risk factor for the development of $\mathrm{AE}$.

Keywords: acute encephalopathy, coxsackievirus A6, enterovirus D68, human parechovirus, human herpesvirus-6, risk factor, viral co-infection

\section{INTRODUCTION}

Acute encephalopathy (AE) is a neurological dysfunction that presents with altered consciousness, sometimes associated with neurological injury or death in young children $(1,2)$. Many etiologic factors have been identified, including infectious agents and genetic factors. AE in young children is often associated with virus infection. The risk factors for developing infantile $\mathrm{AE}$ upon virus infection remain to be determined because infections with the aforementioned viruses usually cause mild symptoms.

Acute encephalopathy in young children is often associated with virus infection, including influenza virus (3-5), human herpesvirus-6 (HHV-6) (6), rotavirus (7), mumps virus (8), and human parechovirus ( $\mathrm{HPeV})$, a newly discovered virus of the Picornavirus family (9). One of the most systematic etiologic studies on AE, in which 983 subjects were examined, was performed in Japan during 2007-2010 (10). The three most frequently detected pathogens were human influenza virus (HIFV, 26.6\%), HHV-6 $(17.0 \%)$, and rotavirus $(4.0 \%)$. Other pathogens were respiratory syncytial virus (RSV), human adenovirus (HAdV), and $\mathrm{HPeV}$. Only five cases showed co-infection with two pathogens, such as HHV-6 and RSV or rotavirus and Campylobacter jejuni. Etiology was undetermined for approximately half of the infant AE cases. Such a study has not been performed in developing countries.

Laboratory technology for detecting pathogens at the nucleic acid level is advancing, and this may provide clues as to the etiology of AE. Here, we describe an infant AE case that may provide insights into this question.

\section{BACKGROUND}

\section{PATIENT HISTORY}

A previously healthy male infant aged 1 year and 9 months presented to a primary physician with fever $\left(38.4^{\circ} \mathrm{C}\right)$. During a physical examination, the infant had a convulsive seizure accompanied by flaccid paralysis of the limbs, upward tonic eye deviation, and tachycardia (190 beats/min). The subject was admitted to an emergency hospital. On arrival, the subject presented with high fever $\left(39.3^{\circ} \mathrm{C}\right)$ and status epilepticus (Figure 1).

\section{LABORATORY EXAMINATION, IMAGING, AND ELECTROENCEPHALOGRAPHY}

Laboratory examinations revealed a white blood cell count of 19,060 cells/ml (neutrophils, 51.1\%; lymphocytes, 43.4\%; and monocytes, $4.0 \%$ ); red blood cell count of 4.42 million cells $/ \mathrm{ml}$; and blood hemoglobin level of $9.5 \mathrm{~g} / \mathrm{dl}$. Most of the serum markers remained within the normal range, including $\mathrm{C}$-reactive protein (CRP), total bilirubin (TB), creatine phosphokinase (CPK), blood urine nitrogen (BUN), and creatinin. Serum levels of aspartate aminotransferase (AST), alanine aminotransferase (ALT), and lactate dehydrogenase (LDH) were slightly elevated. Blood sugar was $240 \mathrm{mg} / \mathrm{dl}$. Serum pro-inflammatory markers interleukin-6 (IL-6) and interleukin-1 beta (IL-1b) were $299 \mathrm{pg} / \mathrm{ml}$ (normal range, $<4.0 \mathrm{pg} / \mathrm{ml}$ ) and $1.4 \mathrm{pg} / \mathrm{ml}$ (normal range, $<10 \mathrm{pg} / \mathrm{ml}$ ), respectively. Cerebrospinal fluid (CSF) was colorless and transparent. CSF glucose, blood cell count, and total protein were within normal ranges. CSF IL- 6 was $40 \mathrm{pg} / \mathrm{ml}$, and IL- $1 \mathrm{~b}$ was undetectable. A cranial computed tomography scan and magnetic 


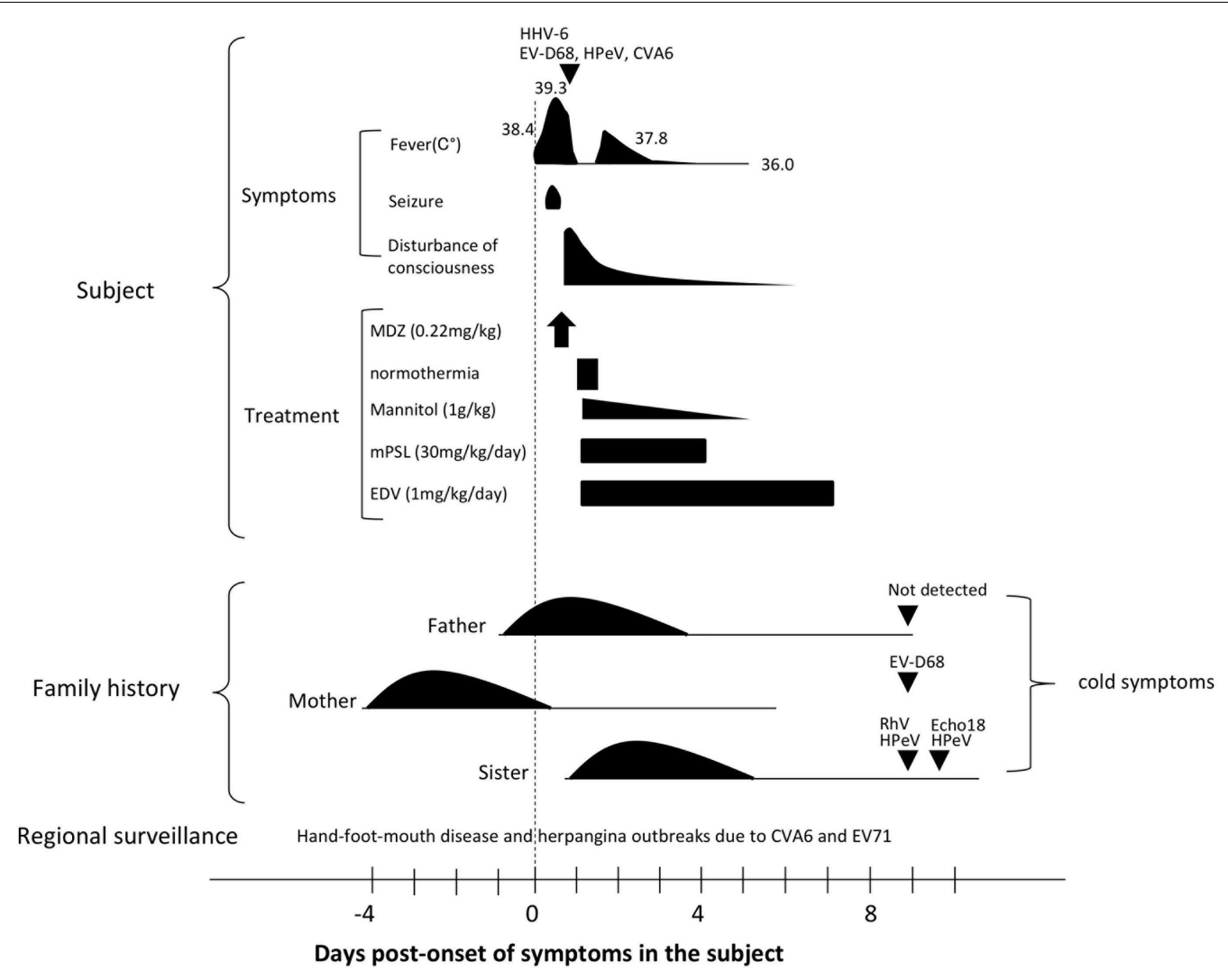

FIGURE 1 | Clinical course of the presented subject and his family history. The triangle indicates the day of specimen collection for the subject. Detected pathogens were indicated above each triangle. Days post-onset refer to the time-course of symptoms in the subject. Please see the main text for details. Abbreviations: HHV-6, human herpesvirus type-6; EV68, enterovirus 68; HPeV, human parechovirus; CVA6, coxsachievirus A6; MDZ, midazolam; mPSL, methylpredonisolone; EDV, edaravone; RhV, rhinovirus; and Echo18, echovirus 18. resonance imaging of the brain without contrast showed no particular findings. An electroencephalogram demonstrated diffuse, high-amplitude slow wave activity.

\section{EXAMINATION OF INFECTIOUS AGENTS}

The blood HHV-6 DNA load was $3 \times 10^{2}$ copies/ml, but HHV-6 was not detected in CSF. The plasma titer for anti-HHV-6 IgG was 1:60, and IgM was undetectable.

Enterovirus species were further examined because of the family history (detailed below) and a hand-foot-mouth disease (HFMD) outbreak in the nursery school where the subject was attending. In addition, regional surveillance revealed HFMD and herpangina outbreaks due to coxsackievirus A6 (CVA6) and enterovirus 71 (EV71) infections. Nucleic acid-based examination and virus isolation tests in tissue culture and suckling mice were performed (11). Enterovirus D68 (EV-D68) was detected in throat swab and stool specimens. $\mathrm{HPeV}$ was also positive for RNA extracted from the throat swab (12). Additionally, CVA6 was positive in the stool. A tissue culture-based virus isolation test detected $\mathrm{HPeV}-1$ from the stool specimen (13). In the suckling mice-based virus isolation test, CVA6 was detected in stool specimen (14). However, CVA6, EV71, and EV-D68 were not detected by nucleic acid-based examination in CSF.

Beside these viruses, immunochromatographic tests were negative for rotavirus, HAdV, and RSV on admission. Nucleic acid-based tests were negative for HHV-7, Japanese encephalitis virus (JEV), vesicular stomatitis virus (VSV), and herpes simplex virus type (HSV) in blood and CSF. Bacterial cultures from blood and CSF were negative.

In summary, four viruses were detected: HHV-6 and three picornavirus species, namely, EV68, HPeV-1, and CVA6 (Figure 1; Table 1).

\section{FAMILY HISTORY}

Four days prior to onset of illness in the infant, his mother presented with cold symptoms. A day before and after the onset of illness in the infant, his father and older sister, aged 3 years and 4 months, also presented cold symptoms. PCR-based laboratory tests revealed that stool specimens from the mother were positive for EV-D68. Three enterovirus species were detected from his older sister: the stool specimen was positive for echovirus 18 (Echo18) and the throat swab was positive for both $\mathrm{HPeV}$ and rhinovirus $(\mathrm{RhV})$. No virus was detected from the patient's father (Figure 1; Table 1).

\section{DISCUSSION}

\section{DIAGNOSIS, TREATMENT, AND OUTCOME}

The differential diagnosis included acute encephalitis, acute meningitis, and non-infectious causes of AE such as toxic or metabolic encephalopathy. We diagnosed this patient as $\mathrm{AE}$ 
Table 1 | Summary of viruses detected in the patient, his family, and regional surveillance.

\begin{tabular}{lll}
\hline Subject & Detected virus & Specimen \\
\hline Patient & CAV A6 & Stool \\
& EV-D68 & Throat swab, stool \\
& HHV-6 & Blood \\
& HPeV & Throat swab, stool \\
Mother & EV-D68 & Stool \\
Father & Not detected & - \\
Older sister & Echo18 & Stool \\
& HPeV & Throat swab, stool \\
& RhV & Throat swab \\
Regional surveillance & CVA6 & HFMD and herpangina patients \\
& EV71 & HFMD and herpangina patients
\end{tabular}

CAV, coxsackievirus; Echo18, echovirus 18; EV71, enterovirus 71; EV-D68, enterovirus D68; HFMD, hand-foot-mouth disease; HHV-6, human herpesvirus-6; $H P e V$, human parechovirus; RhV, rhinovirus.

associated with active infection of four viruses because of the low inflammatory markers. The seizure lasted $52 \mathrm{~min}$, and was stopped by intramuscular administration of midazolam $(0.22 \mathrm{mg} / \mathrm{kg})$. The subject was then administered mannitol infusion $1 \mathrm{~g} / \mathrm{kg}$, methylprednisolone $30 \mathrm{mg} / \mathrm{kg} / \mathrm{day}$, and edaravone $1 \mathrm{mg} / \mathrm{kg}$. Therapeutic normothermia $\left(36.0^{\circ} \mathrm{C}\right)$ for $12.5 \mathrm{~h}$ was also performed. One day post-admission, the subject regained consciousness. However, drowsiness remained until 7 days post-admission. No apparent sequelae were recognized at discharge (Figure 1).

\section{RISK FACTOR OF ACUTE ENCEPHALOPATHY}

This is the first report of four potentially AE-causing viruses detected in an infant with AE (15-18). The subject did not take vaccine and travel abroad recently. The regional surveillance and the family history suggest that EV-D68 was vertically transmitted to the infant from his mother. Considering epidemiologic factors, CVA6 and $\mathrm{HPeV}$ were likely transmitted to the infant at the nursery school. Thus, the infant had been infected with three picornaviruses at once. Given that none of the four viruses were found in all of the specimens from the patients, their viral loads were low compared with viral loads in primary mono-infections partly because replication of the picornaviruses in vivo could have been limited by viral interference (19). Regarding HHV-6, the viral load was relatively low and viral DNA was not detected in the CSF. In addition, plasma IgM against HHV-6 was undetectable. These data indicate that HHV-6 has already established a latent infection although the possibility of HHV-6 primary infection is not eliminated. Simultaneous co-infection with the three picornaviruses could have damaged the immunity of this subject, leading to partial immunosuppression. This might have triggered a reactivation of latently infected HHV-6. The transient immunosuppressive state with active infection of four viruses might have evoked a physiological state akin to a so-called cytokine storm, which can cause $\operatorname{AE}(1,15,20,21)$. Thus, simultaneous infection of viruses might be a risk factor for disease severity, most likely stemming from picornavirus species. These hypotheses require experimental verification in future studies.

\section{CONCLUDING REMARIS}

Picornavirus is often overlooked as an etiological factor for AE. We successfully detected three picornaviruses because we carefully monitored the regional surveillance data and used established, systematized laboratory examination protocols. Laboratory technology to detect pathogens at the nucleic acid level is advancing, and this may provide clues as to the etiology of AE.

\section{AUTHOR CONTRIBUTIONS}

$\mathrm{KN}$ performed the laboratory examinations, drafted, and reviewed the manuscript. MK, MM, SS, CO, and SH examined the subject of interest at the medical institution, performed medical practices, and collected clinical information and specimens. TK and JK coordinated the study. JK supervised data collection, drafted, reviewed, and finalized the manuscript. All authors approved the final manuscript as submitted.

\section{ACKNOWLEDGMENTS}

We thank Kenji Yamazaki (Osaka Prefectural Institute of Public Health) for technical support in viral isolation. This work was partly supported by a grant from Research on Occupational Safety and Health and Emerging and Re-emerging Infectious Diseases, from the Ministry of Health, Labor and Welfare, Japan. Grant numbers: H25-kenki-Ipaan-006 and H25-ShinkoIppan-012.

\section{REFERENCES}

1. Mizuguchi M, Yamanouchi H, Ichiyama T, Shiomi M. Acute encephalopathy associated with influenza and other viral infections. Acta Neurol Scand (2007) 115:45-56. doi:10.1111/j.1600-0404.2007.00809.x

2. Okabe N, Tada Y, Yasui Y. Epidemiology of acute encephalitis or encephalopathy in Japan. Nihon Rinsho (2011) 69:411-6.

3. Amin R, Ford-Jones E, Richardson SE, MacGregor D, Tellier R, Heurter $\mathrm{H}$, et al. Acute childhood encephalitis and encephalopathy associated with influenza: a prospective 11-year review. Pediatr Infect Dis J (2008) 27(5):390-5. doi:10.1097/INF.0b013e31816507b2

4. Gu Y, Shimada T, Yasui Y, Tada Y, Kaku M, Okabe N. National surveillance of influenza-associated encephalopathy in Japan over six years, before and during the 2009-2010 influenza pandemic. PLoS One (2013) 8(1):e54786. doi:10.1371/journal.pone.0054786

5. Okumura A, Nakagawa S, Kawashima H, Morichi S, Muguruma T, Saito O, et al. Severe form of encephalopathy associated with 2009 pandemic influenza A (H1N1) in Japan. J Clin Virol (2013) 56(1):25-30. doi:10.1016/j.jcv.2012.10.007

6. Asano Y, Yoshikawa T, Kajita Y, Ogura R, Suga S, Yazaki T, et al. Fatal encephalitis/encephalopathy in primary human herpesvirus-6 infection. Arch Dis Child (1992) 67(12):1484-5. doi:10.1136/adc.67.12.1484

7. Komoto S, Maeno Y, Tomita M, Matsuoka T, Ohfu M, Yodoshi T, et al. Whole genomic analysis of a porcine-like human G5P [6] rotavirus strain isolated from a child with diarrhoea and encephalopathy in Japan. J Gen Virol (2013) 94(Pt 7):1568-75. doi:10.1099/vir.0.051011-0

8. Watanabe M, Suyama K, Hashimoto K, Sato M, Ohara S, Abe Y, et al. Mumps virus-associated acute encephalopathy: case report and review of the literature. J Child Neurol (2013) 28(2):243-5. doi:10.1177/0883073812441060

9. Hata M, Ito M, Kiyosawa S, Kimpara Y, Tanaka S, Yamashita T, et al. A fatal case of encephalopathy possibly associated with human metapneumovirus infection. Jpn J Infect Dis (2007) 60(5):328-9.

10. Hoshino A, Saitoh M, Oka A, Okumura A, Kubota M, Saito Y, et al. Epidemiology of acute encephalopathy in Japan, with emphasis on the association of viruses and syndromes. Brain Dev (2012) 34:337-43. doi:10.1016/j.braindev. 2011.07.012

11. Hiroaki I, Yasushi S, Mari Y, Kenji S. Phylogenetic analysis and rapid diagnosis of enteroviruses (in Japanese). Rinsyo Uirus (1999) 27:283-93. doi:10.1371/ journal.pone.0036005 
12. Nix WA, Maher K, Johansson ES, Niklasson B, Lindberg AM, Pallansch MA, et al. Detection of all known parechoviruses by real-time PCR. J Clin Microbiol (2008) 46:2519-24. doi:10.1128/JCM.00277-08

13. Pham NT, Trinh QD, Khamrin P, Maneekarn N, Shimizu H, Okitsu S, et al. Diversity of human parechoviruses isolated from stool samples collected from Thai children with acute gastroenteritis. J Clin Microbiol (2010) 48:115-9. doi:10.1128/JCM.01015-09

14. Nix WA, Oberste MS, Pallansch MA. Sensitive, seminested PCR amplification of VP1 sequences for direct identification of all enterovirus serotypes from original clinical specimens. J Clin Microbiol (2006) 44:2698-704. doi:10.1128/JCM. 00542-06

15. Aizaki K, Tsuru T, Okumura K, Kondo N. Three pediatric cases of group A coxsackievirus-associated encephalitis/encephalopathy (in Japanese). No To Hattatsu (2012) 44:397-400.

16. Kreuter JD, Barnes A, McCarthy JE, Schwartzman JD, Oberste MS, Rhodes CH, et al. A fatal central nervous system enterovirus 68 infection. Arch Pathol Lab Med (2011) 135:793-6. doi:10.1043/2010-0174-CR.1

17. Romero JR, Selvarangan R. The human parechoviruses: an overview. Adv Pediatr (2011) 58:65-85. doi:10.1016/j.yapd.2011.03.008

18. Ward KN. Human herpesviruses-6 and -7 infections. Curr Opin Infect Dis (2005) 18:247-52. doi:10.1097/01.qco.0000168386.16519.93

19. Lindenmann J. From interference to interferon: a brief historical introduction. Philos Trans R Soc Lond B Biol Sci (1982) 299:3-6. doi:10.1098/ rstb.1982.0101
20. Kansagra SM, Gallentine WB. Cytokine storm of acute necrotizing encephalopathy. Pediatr Neurol (2011) 45(6):400-2. doi:10.1016/j.pediatrneurol.2011.09.007

21. Singhal G, Jaehne EJ, Corrigan F, Toben C, Baune BT. Inflamasomes in neuroinflammation and changes in brain function: a focused review. Front Neurosci (2014) 8:315. doi:10.3389/fnins.2014.00315

Conflict of Interest Statement: The authors declare that the research was conducted in the absence of any commercial or financial relationships that could be construed as a potential conflict of interest.

Received: 10 December 2014; accepted: 19 March 2015; published online: 02 April 2015. Citation: Nakata K, Kashiwagi M, Masuda M, Shigehara S, Oba C, Murata S, Kase T and Komano JA (2015) A child with acute encephalopathy associated with quadruple viral infection. Front. Pediatr. 3:26. doi: 10.3389/fped.2015.00026

This article was submitted to Neuropediatrics, a section of the journal Frontiers in Pediatrics.

Copyright (c) 2015 Nakata, Kashiwagi, Masuda, Shigehara, Oba, Murata, Kase and Komano. This is an open-access article distributed under the terms of the Creative Commons Attribution License (CC BY). The use, distribution or reproduction in other forums is permitted, provided the original author(s) or licensor are credited and that the original publication in this journal is cited, in accordance with accepted academic practice. No use, distribution or reproduction is permitted which does not comply with these terms. 